\title{
A "Psicologia da Arte" no Olhar de Osório Cesar:
}

Leituras e Escritos ${ }^{1}$

The "Psychology of Art" in Osório Cesar's view: readings and writings

Resumo: Nosso objetivo, neste texto, é contribuir para a pesquisa histórica da formação do pensamento psicológico no Brasil. Para tanto, procuramos, por meio da análise dos escritos de Osório Cesar, apresentar uma síntese de suas formulações teóricas acerca das manifestações artísticas, dentre as quais a produção dos internos do Hospital de Juqueri, entre 1925 e 1955. Nesse intuito, articulamos as idéias emergentes em seus escritos com a pesquisa de sua coleção pessoal de livros. Conclui-se a importância do pensamento desse psiquiatra, que definiu um método preciso de observação das obras de arte em sua constituição bipartite, defendendo e difundindo as idéias psicanalíticas.

Palavras-Chave: Idéias psicológicas, Psicanálise, Estética, psicologia da arte.

Abstract: This article seeks to contribute to the historical research related to the formation of the psychological thought in Brazil. For this, we analyze Osório Cesar's writings in order to make a synthesis of his theories about the artistic manifestations, especially those associated to the production of the Juqueri Hospital patients from 1925 to 1955 . We articulated the emergent ideas in his writings with research done in his own library. We noted the importance of these psychiatrist thoughts, which defined a precise observational

\section{Arley Andriolo}

Bacharel em História pela FFLCH-USP, doutorando no IP-USP com auxílio da FAPESP.

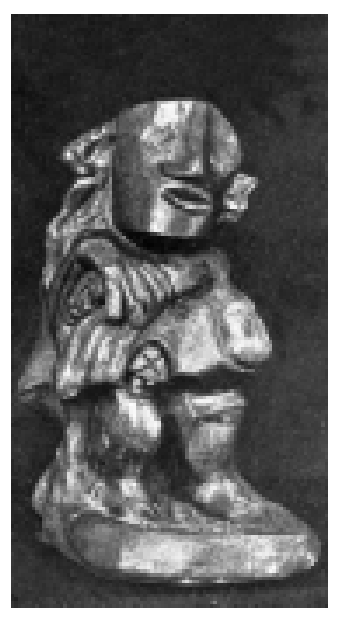
method of the works of art in its bipartite constitution, supporting and spreading psychoanalytic ideas. Key Words: Psychological ideas, Psychoanalysis, Aesthetics, psychology of art.

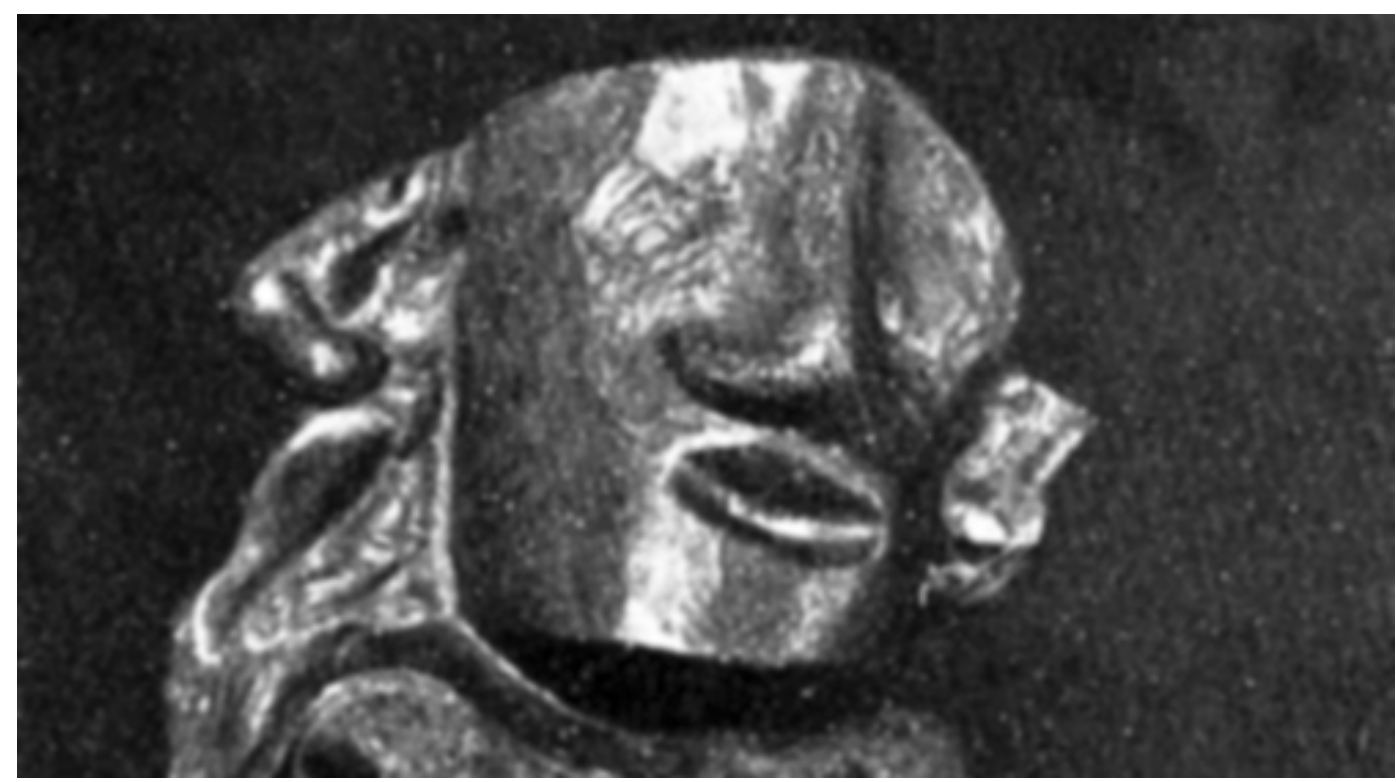

No ano de 1925, o doutor Osório Cesar já dedicava suas atividades profissionais ao Hospital Psiquiátrico de Juqueri, em Franco da Rocha (SP), quando veio a público seu artigo intitulado "A Arte Primitiva nos Alienados". Esse texto foi o primeiro de uma longa série de publicações, entre livros, jornais e revistas, com enfoque especial ao que poderíamos designar genericamente de "psicologia da arte". Ao lado de Mário de Andrade e Durval Marcondes, entre outros, o médico do Juqueri sistematizou ao longo de sua carreira um método de leitura das obras de arte, sobretudo da produção espontânea ocorrida nos pátios dos hospitais psiquiátricos.

Este artigo é fruto de nossa pesquisa de doutorado, desenvolvida no Laboratório de Estudos em Psicologia da Arte do IP-USP (com auxílio FAPESP), em particular do estudo realizado no acervo do Hospital de Juqueri, em Franco da Rocha (SP), entre agosto e novembro de 2001, em cuja biblioteca encontra-se boa parte das obras que compunham o acervo pessoal do médico Osório Cesar, doadas à 
instituição em virtude de seu falecimento, ocorrido em 03 de dezembro de $1979^{2}$.

A psicologia da arte é uma disciplina ainda em formação no Brasil, tanto no campo da própria Psicologia, quanto no das artes visuais. A formulação do enunciado "psicologia da arte" deve, portanto, ser revista com cuidado, em análise que considere as proposições de seu autor em relação a seu contexto histórico, nesse caso, o das primeiras décadas do século XX.

\section{O Psiquiatra do Juqueri}

Osório Thaumaturgo Cesar nasceu em 17 de novembro de 1895, em João Pessoa, Paraíba. Com 17 anos, chegou a São Paulo, onde, quatro anos depois, estava formado em Odontologia. Para sustentar-se nessa época, conta-se, ministrava aulas de violino.

Em 1918, iniciou os estudos de Medicina, interrompido com a extinção do curso em São Paulo, quando se transferiu para a Faculdade de Medicina da Praia Vermelha, Rio de Janeiro, em 1920. Lá, formou-se, aos trinta anos de idade (1925), em Anátomo-patologia. Em 1923, já era interno no Hospital de Juqueri, como "primeiro estudante", e oficialmente como médico em 1925, onde permaneceria por quarenta anos.

A circulação de sua produção intelectual principia em 1919, quando leva a público um opúsculo intitulado Doutrinas Biológicas, obra em que desenvolve um estudo sobre a célula, "o átomo da vida". Com prefácio de Ulisses Paranhos, o livro é dedicado ao intelectual argentino José Ingenieros ${ }^{3}$, considerado por Cesar "o maior filósofo da América do Sul" (Cesar, 1919). É na década seguinte, no entanto, que suas idéias ganham maior amplitude. Em 1922, são editados dois títulos, A Chimica da Vida e Dois Ensaios, este último estudando o "valor biológico das reações das albuminas precipitinas" e as "funções psíquicas". Depois, em 1927, em parceria com J. Penido Monteiro, escreve Contribuição ao Estudo do Simbolismo Mystico nos Alienados: um Caso de Demência Precoce Paranóide num Antigo Escultor (ao que parece, traduzida para o francês e o alemão). Finda a década com sua principal obra, A Expressão Artística nos Alienados (Contribuição ao Estudo dos Symbolos na Arte), publicada em 1929 pelas Oficinas Gráficas do Hospital Juqueri.

Desde então, aparece no meio intelectual paulista como estudioso da Psicanálise, embora não se tenha formado psicanalista. Freqüentou os círculos intelectuais da cidade de São Paulo, sobretudo as reuniões organizadas pelo conhecido senador Freitas Valle: "a quem devo tudo o que sou" (César, 1929).
Na década de 1930, fez estudos em Paris, Alemanha, Itália e URSS, em duas viagens, em uma das quais participou do XV Congresso Internacional de Fisiologia, em Leningrado e Moscou, sob a presidência de Pavlov. Em visita à França, conheceu a assistência aos psicopatas do Centro de Psiquiatria e Profilaxia Mental, Hospital Henri Rousselle, instituição onde procurou encontrar o Dr. Toulouse. Viajou acompanhado de Tarsila do Amaral, então sua companheira.

Seu interesse pelo marxismo é notável, especialmente em dois de seus livros, publicados em 1933, sobre o "Estado Proletário", um ano após o retorno de sua viagem à Rússia. Por conta disto, foi preso político no governo de Getúlio Vargas (Ferraz, 1998). Desse momento de cárcere, temse, entre outros, na Biblioteca do Hospital de Juqueri, o livro de Neves-Manta, O Alcoolismo na Arte e na Psiquiatria (1932), pertencente à coleção pessoal de Osório, constando na página de rosto, além da dedicatória do autor, assinada em 1934, o carimbo do presídio político como "CENSURADA".

A conjugação da Psicanálise e do marxismo é observável nas obras colecionadas. Eric Fromm teve lugar privilegiado, o que se justapõe a esse duplo interesse. Foram identificados treze títulos de Fromm, sobretudo traduções para o português da década de 1960, sendo o mais antigo de 1953.

Além da Psicanálise e do marxismo, o terceiro tema a ocupar as reflexões do médico do Juqueri foi o da arte; poder-se-ia mesmo dizer que esse foi o tema de sua vida, permeando muitas de suas leituras e seus escritos.

Sob essa motivação, escreveu seu primeiro artigo como médico do Juqueri (1925), participou da exposição organizada por Flávio de Carvalho no Clube dos Artistas Modernos, "Semana dos Loucos e das Crianças" (1933), com a palestra intitulada "Estudo Comparativo Entre a Arte de Vanguarda e a Arte dos Alienados". Foi o organizador da I Exposição de Arte do Hospital de Juqueri, realizada no Museu de Arte de São Paulo, em 1948, com obras provenientes de sua coleção pessoal, desenhos a lápis preto e de cor recolhidos dos doentes que "produziam espontaneamente pelos pátios e pavilhões" (Fraletti, 1954, p. 141).

A década seguinte, anos 50, seria fundamental para a prática das exposições de obras de pacientes de hospitais psiquiátricos, da qual se conhece bem as atividades da doutora Nise da Silveira, com o atelier do Centro Psiquiátrico Pedro II (1946) e a criação do Museu de Imagens do Inconsciente (1952). Em Franco da Rocha, com a criação da Seção de Pintura do Juqueri (1949) e a Associação de Assistência aos
1 Trabalho apresentado na mesa "Arte e Loucura" do I Congresso Brasileiro Psicologia: Ciência e Profissão, dia 3 de setembro de 2002, é parte da pesquisa de doutorado em andamento no IP. USP, sob orientação do Prof. Livre Docente João Augusto Frayze-Pereira, com auxílio da FAPESP. Agradecemos ao prof. Artur Andriolo (UFJF) pelas sugestões.

2 Pelo que se sabe, a biblioteca pessoal de Osório Cesar foi dividida em duas coleçôes, uma delas depositada na Biblioteca Municipal Caio Graco da Silva Prado e outra na biblioteca do Complexo Hospitalar de Juqueri (BCHD), ambas em Franco da Rocha (SP). Não se podem mensurar os extravios ocorridos até a completa doação. Agradecemos ao doutor Darío Braz da Silva, responsável pela manutenção da BCHJ, pelo apoio em nossa pesquisa.

3 Autor; entre outra obras, de Principios de Psicologia (Buenos Aires, 1919), A Psychopathologia nos Sonhos e na Arte (Buenos Aires, s. d.), La Psicopatología en el Arte (Buenos Aires, $2^{a}$ ed. 1920). 


\section{"As produções \\ estéticas dos \\ alienados \\ apresentam em \\ parte concepções \\ originais, \\ harmoniosas \\ agradóveis e \\ algumas vezes \\ mesmo sem defeito: \\ em parte essas \\ produções são \\ grosseiras, falhas, \\ incoerentes e \\ revelam um feitio \\ acentuadamente \\ primitivo"}

Cesar

4 Osório Cesar cita essa tese em seu livro de 1929; um exempla original consta no acervo da $B C H J$

5 Carta em depósito do Museu osório César; pode ser consultada em cópia na BCHJ ou em Ferraz (1998, p. 47).

6 Olivro foi resenhado em Paris por Jean Vinchon, no ano seguinte à sua publicação. Ao final, afirma: "[...] La mesure, le goût, le sentiment de la beaute même quand il la rencontre sur le terrain de la pathologie attachent le lecteur; quipardonne aisément certaines lacunes et s'il est Français, se réjouit de retrouver, dans le livre de M. Osorio Cesar; les caractères de cet âme latine qui se maintient malgré les influences que certaine propagande a multipliées pendant les années d'après-guerre" Vinchon, 1930, p. 52).
Psicopatas de São Paulo, realizaram-se várias exposições na capital e interior, não apenas apresentando as obras ao público, como também vendendo-as.

Entre 18 e 27 de setembro de 1950, levou sua coleção particular de obras de internos para a Exposição de Arte Psicopatológica do I Congresso Internacional de Psiquiatria, realizado em Paris, organizada por Robert Volmat. Nesse evento apresentou o texto intitulado "Contribuição ao Estudo da Arte entre os Alienados" e contribuiu com cinqüenta e quatro obras produzidas espontaneamente no Juqueri por autores como Albino Braz, B. Novais, A. Donato, P. Comas (ou Cornas), Sebastião F., entre outros (Volmat, 1956). Dois anos depois, novamente na França, a convite da Maison National de Chareton, Paris, para estudar Psiquiatria Social, ministrou uma palestra na seção consagrada à "arte em Psicopatologia" na Sociedade Médico-Psicológica, sob a presidência de M. G. Collet, cujo resumo foi publicado como "L'Art chez les Alienés dans I'Hôpital de Juqueri" nos Annales Médico-Psychopatologiques (t. 2, n. 5, déc. 1952).

Conforme mencionou Lisbeth Rebolo, que colheu depoimento de Osório Cesar em 1975 (Folha de S. Paulo, 24 fev. 1980), o psiquiatra realizava em sua residência reuniões de artistas, reunindo música e pintura: “[...] Isto é, ouvindo uma música determinada, os artistas fazem apontamentos gráficos e, depois, desenvolvem uma reflexão plástica em torno dessa experiência, em seus ateliês. Dessas reuniões participaram Walter Levy, Aldo Bonadei, Mario Zanini, Carlos Scliar, Gastão Worms, Durval Serra, entre outros de freqüência mais esporádica.[...]" Ouvia-se principalmente Beethoven, Prokoffief e Stravinsky.

\section{Formação Teórica}

Seu primeiro escrito em que se observa o instrumental teórico que poderemos denominar genericamente de "psicologia da arte" é o artigo "Arte Primitiva nos Alienados", publicado pela revista do Hospital de Juqueri, em 1925. Poucos anos antes, foram lançados na Europa os livros marcantes de Walter Morgenthaler (1921) sobre "um artista alienado" chamado Wölfli, e outro de Hans Prinzhorn (1922), psiquiatra de Heidelberg que reuniu a maior coleção de obras de asilo à época. Exatamente na mesma década, os artistas Max Ernst e Paul Klee manifestaram sua fascinação por obras provenientes de hospitais psiquiátricos (Frayze-Pereira, 1995).

No Brasil, pelo que se conhece, esse artigo de Cesar é o segundo texto veiculado sobre o tema. Ulysses Pernambucano, munido de material proveniente do Hospital da Tamarineira, realizou alguns estudos sobre a "arte nos alienados" no início da década de 1920, porém não os teria publicado. Inspirado em
Pernambucano, o jovem médico Sílvio Moura apresentou sua tese de conclusão de curso da Faculdade de Medicina do Rio de Janeiro, intitulada Manifestações Artísticas nos Alienados (1923). Essa tese, embora seja a primeira sobre o tema, teve sua circulação restrita e seu autor não é mais encontrado nos escritos desse domínio ${ }^{4}$.

Desde então, Osório Cesar condena as afirmações sobre exercício mecânico na arte de internos. Para ele, ao contrário: "As produções estéticas dos alienados apresentam em parte concepções originais, harmoniosas, agradáveis e algumas vezes mesmo sem defeito; em parte essas produções são grosseiras, falhas, incoerentes e revelam um feitio acentuadamente primitivo" (Cesar, 1925, p. 111).

Segundo o médico, entre os artistas do Juqueri predominavam os incultos, daí a menor quantidade de literatos que plásticos e picturais. O caso relatado em 1925, de um homem designado como T., trata de um indivíduo "que nunca aprendeu a modelar, e cuja educação intelectual sempre foi medíocre". Toda a sua produção escultórica gira em torno de um mesmo princípio: "o feiticismo, e em algumas delas deixam reproduzir o sentimento atávico evocando a alma dos antepassados de sua raça" (Cesar, 1925, p. 112).

Conclui esse texto recorrendo a Freud, em uma citação sem comentários posteriores, da tradução espanhola de Leonardo da Vinci e uma Lembrança de sua Infância. O artigo foi enviado a Sigmund Freud, cuja resposta de 10 de janeiro de $1927^{5}$ mostra o reconhecimento do pensador de Viena acerca do conteúdo psicanalítico do texto e do desenvolvimento da doutrina no Brasil.

Como mencionamos acima, no ano de 1929, o dr. Cesar levou a público sua obra chave para a questão da arte entre os doentes mentais, o livro $A$ Expressão Artística nos Alienados (Contribuição ao Estudo dos Symbolos na Arte) ${ }^{6}$. Trata-se de um amplo estudo realizado no interior do Juqueri, reunindo o que o médico encontrara de "produção artística" pelos pátios e salas da instituição, trabalho que se iniciara já em 1923, quando, como ele próprio anunciou, "pretendia comparar a arte dos alienados com crianças e primitivos" (Cesar, 1929, p. XXI).

Fora inspirado pela leitura de Prinzhorn (1922) e Vinchon (1924), podendo freqüentar ainda outros autores contemporâneos, como Fursac (1905) e Morgenthaler (1921), além de manter-se fiel a uma determinada leitura freudiana. Na década de 20, o médico realizou muito de sua pesquisa na biblioteca pessoal do doutor Alarico Silveira, onde consultou boa parte das fontes citadas, antes da importação de vasta bibliografia. Com relação ao acervo formado por Osório Cesar ao longo de sua carreira, quando 
não há anotação nas obras torna-se difícil precisar a data do seu ingresso na coleção, mas pode-se supor o interesse despertado por algumas delas, levando-o a adquiri-las, como seria, por exemplo, o caso da primeira edição do livro de Hans Prinzhorn, Bildnerei der geisteskranken: ein beitrag zur psychologie und psychopatologie der gestaltung (1922).

Poderíamos dividir o livro de 1929 em duas partes. A primeira, dedicada a categorizar a obra dos pacientes conforme exemplos extraídos do Juqueri e leituras diversas de textos teóricos sobre o tema, formulando, então, seu "quadro de classificação da arte dos alienados". A segunda parte revela-se a partir do capítulo terceiro, quando realiza correspondências entre algumas doenças mentais e sua suposta manifestação artística característica.

Refletindo sobre a importância dessas manifestações para os pacientes, escreveu que a arte é "... uma necessidade indispensável à sua vida de enclausurado. Talvez seja esse o motivo para que as suas idéias alucinatórias, de grandeza etc., venham a se objetivar demoradamente no mundo da realidade material. E dessa forma nós observamos um fato singular. Os doentes que se entregam a essas cogitações ficam calmos, trabalham com prazer, estilizam as suas manifestações de arte com inteira satisfação de ânimo. Dir-se-ia que os seus pensamentos se perdem num enorme mundo de belezas" (Cesar, 1929, p. 35).

Seu modelo de classificação é citado ao lado do de Prinzhorn na breve história das idéias de arte e loucura escrita por Robert Volmat (1955). Não obstante algumas alterações em textos posteriores, a concepção do quadro e seu intento em comparar a produção dos internos com manifestações artísticas outras se mantém. O método comparativo, como mencionado, pretendido por Cesar desde 1923, tem base em uma leitura de Cesare Lombroso, o primeiro a notar a semelhança das obras de alienados com a primitiva (Cesar, 1929). Prinzhorn também o aplicara em 1919 e $1922^{7}$.

Tal método funcionava, com Osório Cesar (1929), por exemplo, na observação da seção feminina, onde são fabricadas bonecas com trapos velhos e papel, em um gosto comparável ao dos índios Karajás, cujas bonecas foram encontradas na ilha do Bananal em outubro de 1927. A música, em outro exemplo, capaz de despertar até animais, muito comum entre os "primitivos", como entre os botocudos e os parecis, é relacionada com a sua prática entre os alienados.

São quatro grupos: 1) arte do primitivo (desenho e música), 2) arte primitiva ou arcaica (desenho, escultura, decoração, poesia, música, dança), 3) arte clássica ou acadêmica (desenho, pintura, escultura, decoração, poesia, música, dança), 4) arte de vanguarda (desenho, pintura, escultura, decoração, poesia, música, dança).

Cada grupo do quadro corresponde a um "estilo". As obras dos internos eram comparadas com esses "estilos" e, então, classificadas. A comparação, no entanto, não é rígida, podendo uma obra, em alguns casos, oscilar entre "estilos" diferentes, como, por exemplo, comparando uma obra à "arte primitiva" e também à "arte cubista".

Pela leitura psicanalítica proposta, a análise do material visual em Osório Cesar resulta sempre no exame dos símbolos ali contidos. O simbolismo que se definira como "primitivo", visto nas classificações de "arte do primitivo" e "arte primitiva", dado seu estreito interesse pelas formas de regressão, será central nos textos do psiquiatra. A idéia de "primitivo" ocupa lugar privilegiado nesse modelo classificatório, tanto assim o é que, nos anos 50, Cesar reformula esse modelo, possibilitando à idéia de primitivismo permear três das quatro categorias apresentadas.

As produções do grupo que designa como "acadêmicas" ou "clássicas", devido a sua objetividade, são pouco simbólicas e, portanto, não Ihe interessam: "[muitas vezes], a arte dos alienados é uma arte normal, bem equilibrada, e por isto mesmo sem grande interesse para o nosso estudo a não ser no tocante a um ou outro ponto de concepção original que ela possa ter. Por isso, comparamos as manifestações artísticas dos alienados que pertencem a esse grupo com a arte comum, a arte acadêmica" (Cesar, 1929, p. 24).

Ao contrário, a arte de vanguarda será de extrema importância para o psiquiatra, pois, ao lado da "arte primitiva", fornece os elementos necessários para a leitura simbólica das obras de seus pacientes. O tema da "arte nos loucos e vanguardistas" ocupou todo um livro de Cesar, escrito em 1934. Essa questão já fora enunciada em 1925, quando escrevera: "A estética futurista apresenta vários pontos de contato com a dos manicômios. Não desejamos com isso censurar essa nova manifestação de arte; longe disso. Achamo-la até muito interessante, assim como a estética dos alienados. Ambas são manifestações de arte e por isso são sentidas por temperamentos diversos e reproduzidas com sinceridade" (Cesar, 1925, p. 117).

Quando não identificados precisamente, os movimentos de vanguarda são analisados por Cesar sob o termo genérico de "futurismo", como era corrente à época no Brasil. "O futurismo veio quebrar as cadeias do classicismo, estribando-se nas manifestações artísticas primitivas." Registra que as obras de vanguarda "... exprimem, dentro de seu intrincado primitivismo, os complexos subconscientes de seus autores, que aparecem mascarados no
7 Sobre o método de comparação entre obras de arte utilizado por psiquiatras no início do século $X X$, apresentamos o trabalho intitulado "História da Interpretação Psicopatológica da Arte: Chaves Teóricas e Método Comparativo", no III Simpósio Nacional de Filosofia da UFOP, Ouro Preto (MG), julho de 2002, a ser publicado. 
simbolismo da deformidade." Por fim: "Há muita gente por aí que sustenta a insinceridade dos artistas de vanguarda. Não penso dessa maneira. Acho até e muito naturalmente que eles estejam profundamente compenetrados nessa revolucionária manifestação artística. [...]" (Cesar, 1934, pp. 21, 15 e 26).

\section{A Leitura Psicanalítica de Cesar e a Obra de Arte}

Bem entendido, a "psicologia da arte" elaborada pelo doutor Osório Cesar é substancialmente uma leitura freudiana de arte. Foram sete os livros do fundador da Psicanálise localizados no seu acervo (o que não significa que teve apenas esses sete exemplares), dos quais o mais antigo é uma tradução francesa, Trois Essais sur la Théorie de la Sexualité (Paris, 1923). No caso específico da arte, referiu-se, no seu primeiro texto de 1925, a Leonardo da Vinci e uma Lembrança de sua Infância, de uma tradução espanhola das Obras Completas.

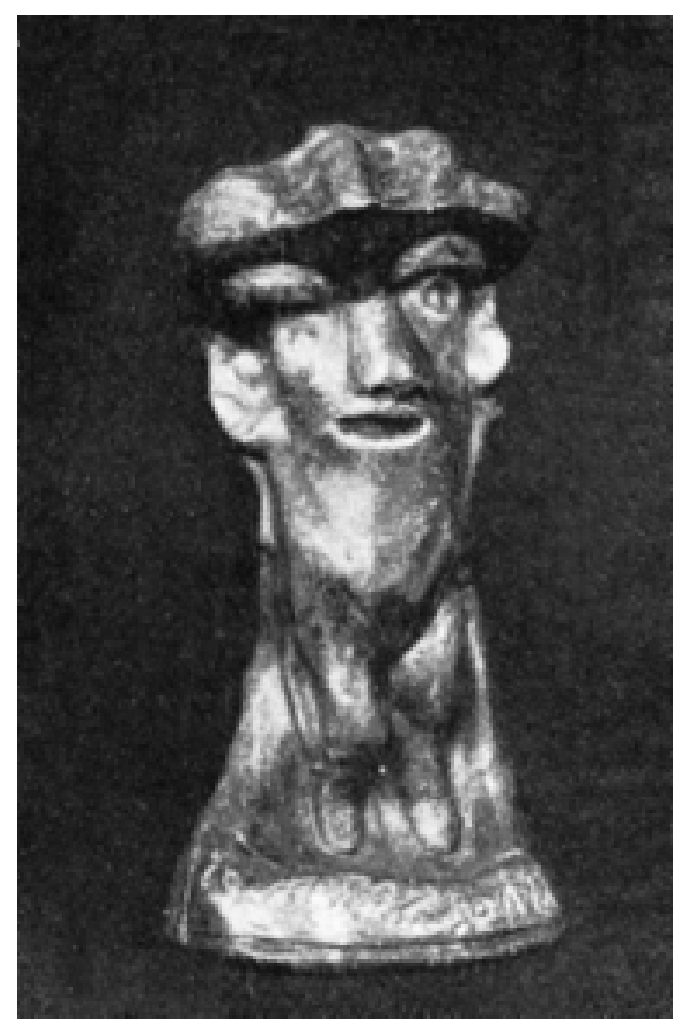

Embora tenha lido e citado ao longo de sua carreira obras de Carl Jung, pensador que comparece com doze títulos no seu acervo, dos quais o mais antigo identificado data de 1944, essa orientação parece não ter deixado marcas importantes em seus textos. A citação desse autor é feita por Osório Cesar apenas no artigo escrito com Durval Marcondes (1928), inserido no livro de 1929. Trata-se da obra intitulada Der Inhalt der Psychose (2ª ed., 1914) justamente o mesmo citado por Marcondes em outros textos (Marcondes, 1933).

Do formalismo, seja na interpretação de Hans Prinzhorn (dois títulos no acervo), seja em seus fundadores com Kurt Koffka (uma obra no acervo), utiliza-se apenas de algumas considerações sobre a origem do gesto artístico, mas sem grande interesse. Sua análise permanecerá vinculada aos textos psicanalíticos, àqueles que se dedicaram à "analise retrospectiva da gênese emotiva na criação da obra de arte" (Cesar, 1944, p. 4).

O intelectual brasileiro opera, pois, com a noção de inspiração poética em relação ao funcionamento das fantasias infantis e dos sonhos, ou seja, para ele arte é compensação, realização na fantasia daquilo que o real negou. Para Cesar, as orientações de Freud no campo das artes não se constituem em um corpo de doutrina propriamente dito para essa questão; no entanto, além dos textos do fundador da Psicanálise, trabalha com idéias provenientes de Oskar Pfister e Otto Rank.

Não obstante, dos autores freudianos, pelo menos dois são fundamentais à formação do pensamento do psiquiatra do Juqueri: Charles Baudouin, com Psychanalise de l'Art (1929) e o intelectual espanhol Gonzalo Lafora, sobretudo no artigo "Estudio Psicológico del Cubismo y Expressionismo" (1922). Nesse contexto, para César, toda obra de arte possui duas partes principais, distintas, mas diretamente interligadas: 1) o "conteúdo manifesto" e 2) a "significação latente".

A primeira parte, o conteúdo manifesto, é a que se destaca aos olhos e que o público em geral compreende; trata-se do "... lado estético da obra, sua camada exterior, a técnica do artista, seu estilo etc. [...] Tudo isso significa apenas a expressão superficial e exterior, o lado do revestimento que cobre o verdadeiro sentido do motivo da inspiração artística" (Cesar, 1944, p. 4).

A segunda, a significação latente: “... é a parte íntima da obra de arte, o seu lado simbólico, a fantasia que mascara os impulsos inconfessáveis da vida íntima do artista e somente a ele o interessa. Ao artista portanto está reservada essa parte obscura de seu trabalho" (Cesar, 1944, p. 4).

A predominância de uma das partes implica a sua compreensão no sentido "clássico", "objetivo", "realista" (com predomínio da primeira), ou em um "sentido obscuro", "subjetivo", "idealista" (com predomínio da segunda). Torna-se importante observar, segundo essa proposta, que é a obra que determina o modo de interpretação do espectador, não o contrário. Por exemplo, na arte naturalista e acadêmica da primeira metade do século XIX, destaca-se o conteúdo manifesto, evidência de seu 
caráter objetivo. Nas chamadas "vanguardas históricas" das primeiras décadas do século XX, ao contrário, vêem-se obras individualistas por excelência, projetando-se mais a significação latente.

Identificadas essas duas partes, no seu trabalho de olhar a obra, passa-se a examinar o significado simbólico das imagens. Considera que as fantasias e os devaneios servem de máscara aos impulsos e complexos: "Na inspiração artística, vemos, por uma análise aprofundada da vida e das obras dos grandes artistas, os desejos reprimidos aparecerem do subconsciente e se mostrarem apagados em símbolos ou temas diversos em todas as suas produções [...]" (Cesar, 1934, p. 29). Em outro texto: "Tudo o que de oculto o interessa lança o artista simbolicamente na sua obra, tornando-a assim uma estilização suma, chegando por vezes até a mais elevada abstração não compreensível pelo público em geral porque é representação inteiramente individual de suas emoções interiores, de seus recalques. [...] Essa arte subjetiva é completamente independente da realidade humana coletiva [...]" (Cesar, 1944, p. 4).

Assim entendido, arte não é expressão social nem coletiva como poder-se-ia concluir por outras formas de interpretação da arte: sociológica, naquilo que se define como "anestético", ou psicológica junguiana, pautada em "imagens arquetípicas". A obra de arte, para Cesar, "representa apenas os desejos individuais, pessoais, de um grupo de artistas, disfarçados de elementos simbólicos representativos das imagens do inconsciente" (Cesar, 1944, p. 4).

Com essa análise, o médico do Juqueri propunha uma inversão ao método denominado "histórico", da filosofia de Taine, herdado do século XIX, que partia do geral (idéia) para o particular. Em seu livro de 1934, propõe a prática do que seria o "método da psicologia individual", em uma técnica de análise inspirada por Lafora (1922), pela qual se analisa a obra de arte do particular para o geral.

Assim, teríamos: “... em primeiro lugar estuda-se o homem vivo, interroga-se o porquê de suas formas várias de atividade, das que se conseguem uma explicação psicológica e logo trata-se de explicar comparativamente os fatos antigos e aprofundar mais no segredo dos modernos" (Cesar, 1934, p. 29).

\section{A Obra dos Alienados}

Para compreensão das obras produzidas no interior do Hospital de Juqueri, a formulação teórica apontada pelo psiquiatra é a mesma que lhe permitiu pensar os artistas profissionais. "Os símbolos que os doentes usam para as suas produções artísticas pertencem à simbologia que Freud observa na interpretação dos sonhos. Assim, os órgãos genitais masculinos são, por exemplo, representados por bengalas, limas, serpentes, punhais, revólveres, torneiras, dirigíveis Zepelim, peixes etc. Os órgãos femininos têm sua representação em vasos, caixas, cofres, portas, frutos etc" (Cesar, 1929, p. 27).

Para Cesar, muito das manifestações artísticas nos alienados é fruto de atavismo, ou seja, regressão a épocas arcaicas. Trata-se da tese da filogenética, observada em Freud, para quem os conflitos sexuais recalcados são ecos de comportamentos primitivos. Cada indivíduo manifestaria em Estética e em Fisiologia o desenvolvimento da espécie.

"O homem primitivo - escreveu Cesar - é de índole profundamente supersticiosa. Todos os fenômenos da natureza que ele observa tem uma expressão de terror manifesto na sua mentalidade. Dessa maneira ele interpreta o trovão, o raio, as chuvas copiosas etc. Vem daí, talvez, a necessidade da criação do símbolo origem da arte - para amenizar esse primeiro sofrer representando já o esboço de uma filosofia elementar da vida. E essa filosofia torna-se código de vida em certas comunidades primitivas atuais com os totens e tabus" (Cesar, 1955, p. 128; grifos no original).

O simbolismo, como se disse, tem seus estudos fundamentados nos sonhos. Cesar refaz a leitura freudiana, podendo afirmar, com Lewis, o fator filogenético na herança de símbolos de civilizações primitivas: "Da mesma maneira que se estuda o pensamento simbólico no sonho [,] também no artista que, segundo Freud, é um introvertido próximo à nevrose, o estudo analítico do simbolismo estético possui idêntico valor da interpretação onírica. Tanto é assim que Freud, n'um longo e curioso trabalho analítico sobre Leonardo da Vinci, conseguiu descobrir nos seus quadros, os anseios reprimidos de sua infância" (Cesar, 1934, p. 52).

Não obstante a relação que estabelece com o ato criador no artista comum, há uma inclinação para exteriorizações plásticas nos internos que não haveria na vida normal. Conforme Lafora (1922), isso se deve a dois fatores, um interno e outro externo. O primeiro, interno ao doente, devido à psicose que o afasta do mundo exterior criando um mundo próprio, no autismo definido por Bleuler. $O$ segundo, de ordem exterior, é promovido pela clausura, pelo ambiente dos pavilhões e pela falta de atividade.

Em 1951, um ano após divulgar a produção de seu paciente Albino Braz em Paris, autor de desenhos com "o mais rico simbolismo freudiano que se possa imaginar", o psiquiatra sintetizou: "Realizando seus trabalhos, os doentes mentais decompõem a realidade, transformando-a em combinações arbitrárias, alterando assim as normas de nossa percepção visual [...]" (Cesar, 1951, p. 56) $)^{8}$. O ritmo e a estilização notados nessas obras, sobretudo entre os esquizofrênicos, fazem com que elas se pareçam às de crianças e de "primitivos", o que permitia a Cesar
A partir do momento que um outro dirige a palovra a alguém há a curiosidade e necessidade de saber o que pensamos a respeito e muitas vezes o nãoverbalizado

impossibilita a capacidade de ligação de fatos que não puderam até então ser compreendidos.

8No original: "En réalisant leurs travaux, les malades mentaux décomposent la réalité la transformant en combinations arbitraires, altérant ainsi les normes de nos perceptions visuelles[...]" (trad. do autor). 
concluir tratar-se da representação da significação latente do pensamento mágico do doente.

"Nos artistas, literatos, poetas e escritores normais, o temperamento 'autista' é também muito desenvolvido. Neles, a facilidade com a qual mergulham em sua tendência ao sonho é como a de todos nós; de lá, eles retiram idéias preciosas as quais exteriorizam no charme de uma obra de arte" (Cesar, 1951, p. 57) .

O caso de um interno designado apenas por T., citado em 1925, 1929 e 1934, é exemplar desse modo de interpretação da obra produzida no Juqueri, que reúne à sua leitura simbólica psicanalítica a noção de atavismo, revelando um discurso por vezes contraditório da explicação psicológica das obras de arte.

T. possuía 32 anos em 1925, "preto, soldado de polícia, casado, católico, brasileiro, procedente da Cadeia Pública". Ingressou no Hospital de Juqueri a 2 de julho de 1919. Seu pai morrera há 22 anos, mas a mãe e quatro "irmãos normais" continuavam vivos. Sob a ótica da criminologia daquele início de século, registrada na observação médica de 2 de fevereiro de 1919, T. portaria no corpo "diversos estigmas de degeneração, tais como a assimetria craniana, orelhas pequenas e abauladas, abóbada palatina funda e pés chatos" (citado em Cesar, 1925, p. 113).

Perturbado por um "agente" que o dominava "mudando o seu pensamento e dando-lhe choques elétricos pelo corpo", certo dia "ficou cloroformizado e as telefonagens o obrigavam a matar a mulher". Consumou o ato criminoso, motivo pelo qual fora preso. No hospital, porém, os "agentes" continuavam a atormentá-lo. Aborrecem-no com o cantar semelhante a um galo ou latindo como um cachorro (Cesar, 1925, p. 113).

littérateurs, poètes et écrivains normaux, le tempérament 'autistique' est aussi très développé. Chez eux, la facilite avec laquelle ils plongent dans leur tendance au rêve, est comme de nous tous; de là, ils retirent des idées précieuses qu'ils extériorisent dans les charmes d'une oeuvre d'art." (trad. do autor).

10 Para Cesar; "fetichismo", tomada do francês, é um equívoco. O correto, para esse autor, seria "feiticismo" de acordo com a origem portuguesa do termo. Derivada de feitiço, foi empregada pela primeira vez por exploradores da Guine referindo-se aos objetos próprios de superstiçoes e ritos africanos, como escreveu Fernando Ortiz (Glossário de Afronegrismos) (Cesar; 1925). modelando em barro "figuras grotescas de uma originalidade palpitante e de um realismo disforme". Uma figura de barro esculpido $(21 \mathrm{~cm}$, localização desconhecida), tem na base o nome $S$. Jacinto gravado. O autor da escultura dizia tê-la construído com "O ouro mais puro da mina que encontrei no terreiro", possuindo ela a virtude de "espalhar felicidade entre os homens". A cabeça da imagem estava coberta por um boné, tendo no alto uma cruz, os olhos empapuçados; o nariz desajeitado e chato cai em diagonal sobre a boca semi-aberta. Uma longa barba cobre do queixo até o abdômen. Não são vistos os braços e as mãos, enquanto as pernas são curtas e desengonçadas. olhos são duas pedras pequenas de granito embutidas nas órbitas. Para o autor da imagem, "são dois raros diamantes" (Cesar, 1925, p. 114).

O que há de notável nas obras de T., como sua qualidade dominante, pondera o psiquiatra, "é seu forte individualismo feiticista" ${ }^{10}$. Apesar de contestar, como vimos, a idéia de arte como manifestação de psicologia coletiva, observa que, pelo fato de T., não obstante nascido no Brasil, ter ascendência africana, lugar onde abunda a crença nos feitiços, "em virtude dessa herança atávico-religiosa, será lícito pensar que essas esculturas modeladas em barro por T., com virtudes místicas, nada mais são que o resultado da explosão de crenças feiticistas de seus antepassados, somente agora despertadas em razão de seu estado mental" (lbid, p. 120).

O símbolo das mãos da escultura de Santo Antônio da Rocha é lido como uma manifestação de "simbolismo sexual", "recordação de práticas infantis". Apesar de os médicos apurarem que T. não era no hospital um onanista, o exame retrospectivo diria que esse "vício" lhe era comum na vida pregressa. Continua: "No nosso doente, encontramos além de um sentimento artístico feiticista, recordações de atos de sua infância, que surge do sub-consciente e que ele plasma no barro sob a forma de símbolo. Tal é a origem do acabamento escultórico rico das mãos da estranha estátua..." (Ibid, p. 121).

A conclusão de Osório Cesar da análise da obra de T. vale como síntese de sua proposição para a leitura psicológica da arte nos alienados: "A arte de T. é uma arte do primitivo; grotesca, feiticista, com representação simbólica sexual. Encontra-se nela semelhanças acentuadas com a arte cubista. [...] A manifestação artística neste doente, cuja educação intelectual é muito rudimentar, constitui também um eco atávico de lembranças feiticistas dos seus antepassados, somente agora aparecida em conseqüência do seu desequilíbrio mental" (Ibid, p 124).

Em outra obra, um Santo Antônio da Rocha (barro esculpido, $31 \mathrm{~cm}$, localização desconhecida), de mãos protuberantes e bem traçadas, "notam-se sinais simbólicos em forma de cruz em baixo das mãos. Os

\section{Conclusão}

Entender a obra de arte no sentido apresentado por Osório Cesar foi parte essencial da implantação de novos modos de interpretação da arte na primeira metade do século XX, como o fora a Semana de Arte Moderna, reorientando as posições dos grupos no interior do campo das artes visuais.

Evidentemente, observando com nossos olhos contemporâneos, encontraríamos ali pontos delicados e passíveis de crítica, como o seria, por exemplo, diante do seu método comparativo, analisando obras de doentes mentais em relação ao que se entendia como "povos primitivos", na observação sintomatológica de certas obras, na oposição extrema entre o "método psicológico" e 
"método histórico" ou, ainda, na interpretação simbólica generalizante em relação ao simbolismo sexual. Enfim, praticava-se uma leitura psicológica da obra de arte que Frayze-Pereira denominou de "selvagem" ${ }^{11}$.

No entanto, para se ler os escritos do doutor Osório Cesar, como quaisquer outros herdados do passado, será necessário extrair de nós mais de cinqüenta anos de história do conhecimento da Psicologia e da arte. Isso quer dizer que, não obstante a estranheza que nos possam causar certos modelos de análise, seu sentido está no contexto histórico e ideológico particular, neste caso, as primeiras décadas do século XX.
Osório Cesar localiza-se, pois, no início de um quadro histórico que passa, posteriormente, pelas proposições formalistas de Mário Pedrosa, na sua concepção de "arte virgem", pela interpretação da Psicologia Analítica nas "imagens do inconsciente", de Nise da Silveira, para chegar a leituras contemporâneas, como nos estudos de recepção empreendidos por Frayze-Pereira e suas "visões do abismo". Trata-se da controversa história da formação do campo da psicologia da arte no Brasil, sobretudo no olhar que lançou sobre a obra do Outro.
Arley Andriolo

R. Vitorino Carmilo, 830, apto. 163-B, Campos Elíseos, São Paulo, SP, CEP: 01153-000.E-mail: arley@usp.br

Recebido 28/10/02 Aprovado 02/01/04

BAUDOUIN, C. Psychanalyse de l'Art. Paris: Alcan, 1929

CESAR, O. Doutrinas Biológicas (ACellula. OÁtomo de Vida). São Paulo: Pocai, 1919.

CESAR, O. A Chimica da Vida (Ensaios Filosóficos). São Paulo: Livraria Santos, 1922

CESAR, O. Dois Ensaios. São Paulo: Lealdade, 1922.

CESAR, O. A Arte Primitiva nos Alienados: Manifestação Esculptórica com Caracter Symbolico Feiticista num Caso de Syndroma Paranóide. Memórias do Hospital de Juquery, São Paulo, ano 2, no. 2, 1925, pp. 111-125.

CESAR, O. A Expressão Artística nos Alienados. (Contribuição Para o Estudo dos Symbolos na Arte). São Paulo: Officinas Graphicas do Hospital de Juquery, 1929.

CESAR, O. Onde o Proletariado Dirige...(Visão Panorâmica da Rússia Soviética). S. Paulo: s. ed., 1933.

CESAR, O. Que é o Estado Proletário? São Paulo: Edição Udar, 1933.

CESAR, O. A Arte nos Loucos e Vanguardistas. Rio de Janeiro: Flores \& Mano, 1934.

CESAR, O. Como se Deve Compreender uma Obra de Arte. O Estado de S. Paulo, 18 nov. 1944, p. 4

CESAR, O. Contribution à l'Étude de l'Art Chez les Alienés. Arquivos do Departamento de Assistência a Psicopatas do Estado de São Paulo, Franco da Rocha, vol. XVI, jan.-dez., 1951, pp. 51-64.

CESAR, O. A Expressão Artística nos Alienados. Boletim de Psicologia São Paulo, ano VI, set./dez. 1954 e mar./jun. 1955, no. . 21-24, 1955, pp. 125-137.

CESAR, O.; MARCONDES, D. Sobre Dois Casos de Estereotypia Graphica com Symbolismo Sexual. Memórias do Hospital do Juquery, ano III-IV, no. 3-4, 1928, pp. 161-165.
FERRAZ, H.. C. Arte e Loucura: Limites do Imprevisível. São Paulo: Lemos, 1998.

FRALETTI, P. Considerações Sobre a Arte dos Alienados e dos Artistas Modernos. Arquivos do Departamento de Assistência a Psicopatas do Estado de São Paulo, v. XX, no. 3-4, jul./dez., 1954, pp. 139-173.

FRAYZE-PEREIRA, J. A. Olho D'Água: Arte e Loucura em Exposição. São Paulo: Escuta, 1995.

FRAYZE-PEREIRA, J. A. O Desvio do Olhar: dos Asilos aos Museus de Arte. Psicologia USP, vol. 10, no.2, 1999, pp. 47-58.

LAFORA, G. R. Estudio Psychologico del Cubismo y Expressionismo. Archivos de Neurología, Madrid, t. 3, no. 2, 1922, pp. 119-155.

LEMOS, F. C. O Médico, o Louco e o Artista. Folha de S. Paulo, 24 fev. 1980.

MARCONDES, D. A Psicanálise dos Desenhos dos Psicopatas. Revista da Associação Paulista de Medicina, v. 3, no. 4, out., 1933, pp. 175-182.

MOURA, S. B. Manifestações Artísticas nos Alienados. These apresentada à Fac. de Medicina do Rio de Janeiro. Rio de Janeiro: Off. Graph. do "João Pestana", 10 nov. 1923.

PRINZHORN, H. (1922). Expressions de la Folie: Dessins, Peintures, Sculptures d'Asile. Paris: Gallimard, 1984.

VINCHON, J. L'Art et la Folie. Paris: Stock, 1924

VINCHON, J. Un Essai d'Explication Symbolique de l'Art des Aliénés. Le Progrès Médical, Paris, 7e année, no. 7, 1930, pp. 49-52.

VOLMAT, R. De l'Évolution des Idées sur "I'Art et la Folie". Histoire de la Médecine, ano 5, no. 1, jan., 1955, pp. 29-49.
Referências 